\title{
The Impact on Child Developmental Status at 12 Months of Volunteer Home-Visiting Support
}

\author{
Jacqueline Barnes \\ Department of Psychological Science, Institute for the Study of Children, Families and Social Issues, \\ Birkbeck University of London, Malet Street, London WC1E 7HX, UK \\ Correspondence should be addressed to Jacqueline Barnes, jacqueline.barnes@bbk.ac.uk
}

Received 17 October 2012; Revised 5 November 2012; Accepted 6 November 2012

Academic Editor: Masha Gartstein

Copyright ( $(2012$ Jacqueline Barnes. This is an open access article distributed under the Creative Commons Attribution License, which permits unrestricted use, distribution, and reproduction in any medium, provided the original work is properly cited.

Home-visiting support during pregnancy or soon after the birth of an infant can be advantageous for maternal well-being and infant development. The best results have been identified when home visitors are professionals, especially nurses, and if a theoretically driven curriculum is followed with fidelity. Some suggest that disadvantaged families, who may avoid professional services, respond well to support from community volunteers, but there is less evidence about their impact. This study identified potentially vulnerable mothers during pregnancy in randomly allocated neighbourhoods where local volunteer home-visiting schemes agreed to offer proactive volunteer support and control areas where the local home-visiting schemes did not offer this proactive service. Taking demographic, child, and family factors into account, there were no significant differences in infant cognitive development at 12 months of age between families who had been supported by a volunteer and those who had not. Better cognitive development was predicted by less reported parenting stress when infants were 2 months and a more stimulating and responsive home environment at 12 months. The results suggest that unstructured proactive volunteer support for potentially vulnerable families is not likely to enhance infant development. Limitations of the cluster-randomised design are discussed.

\section{Introduction}

Based on evidence from studies of early brain development (e.g., $[1,2])$ and interventions in the USA such as Early Head Start [3], there has been an increasing emphasis in the UK on offering early intervention designed to enhance infant development and increase family well-being, especially to disadvantaged families $[4,5]$. Many experts have highlighted the importance of intervening in early childhood with vulnerable families to ensure that children can develop to their full potential. In infancy, brain development is rapid, and there is most likelihood that development can be enhanced, which means that the return on investments is also likely to be greatest [6-8]. Interventions with the most impact on child outcomes generally involve centre-based provision of a carefully designed curriculum, such as the Abecedarian program [9] and the Perry Preschool project [10]. However, programmes incorporating home-based services for vulnerable populations have demonstrated their effectiveness particularly when they are offered proactively, either prenatally or at birth [11]. The combination of both home-based visits and centre-based services can be particularly effective, such as the Infant Health and Development Programme in the USA which was offered in the context of a randomised control trial to parents of low-birth-weight infants (e.g., [12]). However, such comprehensive experimental programmes are generally too costly to incorporate into existing services. In addition, it is not clear which aspects of complex interventions-including support to parents at home, a day care place for the child, parenting groups, or additional child health checks - are most closely associated with improved outcomes. It was suggested some years ago [13] that trials could take one element of this kind of comprehensive intervention at a time, compared to existing services, to determine any beneficial impact.

There is some evidence that effects of different elements of interventions can be additive. For instance, the Early Head Start intervention randomly assigned families to receive home-visiting support and child educational services in a group, or only one of these. Children and parents in families 
receiving both home-visiting and centre-based child care showed most improvement, while centre care alone led to more improvement for children, and home visiting had more impact on parenting and the home environment [3].

Timing of support may be important. A review of early interventions concluded that support might be particularly useful when the first contact is made during pregnancy, providing a means of establishing positive relationships between families and service providers in the community [14].

There has been debate regarding whether professionals should offer support to parents or whether the same impact could be achieved by (less expensive) paraprofessionals, and results are contradictory [15]. A systematic review of home-based social support provided by nonprofessionals for socially disadvantaged mothers who had recently given birth [16] concluded that there are benefits to capitalising on experienced mothers in the community, both in terms of cost and cultural sensitivity, in comparison with purely hospital-based programmes led by teams of health care professionals. In a review of parenting support, Moran et al. [17] categorised support as informal (neighbours, family), semiformal (community organisations, the voluntary sector), and formal (professional services). Both Moran et al. [17] and a more recent review [18] concluded that formal interventions with a strong theory base and a clearly articulated model may be the most effective, with the most potential to influence child outcomes. Nevertheless, a UK parent survey found that informal support was preferred to that from "expert" formal sources [19]. In particular, "hard to reach" and vulnerable families may respond better initially to support from other parents rather than from professionals, providing the potential for community parent support to be a "gateway" to more intensive services if necessary [5].

The question of whether or not visits are structured, following a clear curriculum, is also relevant. There is a range of evidence that professional home visiting using structured materials can significantly improve parenting and child outcomes. The most rigorously evaluated home-visiting intervention, the Nurse Family Partnership Programme [20], has a wide range of materials and involves regular visits from pregnancy until infants are 24 months. It has proved particularly beneficial in the USA for young and/or single women of low SES $[21,22]$. In the UK, structured social support from a community midwife was provided during pregnancy, targeting mothers at risk for low birth weight [23]. The intervention had a beneficial impact on maternal and child health outcomes. A combination of visits from community volunteer, a nurse, and a social worker has also been the subject of a randomised trial, with the professionals giving advice and the volunteers providing support [24]. Mothers reported fewer psychological symptoms and made greater use of services. The Bristol Child Development Programme [25] offered support and encouragement through health visitors visiting monthly postnatally for one year, exploring issues such as diet, health, and maternal self-esteem, and it has been incorporated into health visitor practice in some areas, but no evidence from trials is available. Thus, there is substantial potential to improve child and family outcomes from home visiting using approaches that specify the frequency and number of visits and provide a range of materials.

It has been found that "community mothers" who are not health professionals can be effective in delivering a structured programme originally intended for use by professionals. A randomised trial in Dublin assessed the impact of the Bristol Child Development Programme for families with new-born infants living in disadvantaged neighbourhoods when delivered by community mothers, finding significant benefits for mothers and children [26]. Intervention children received more immunisations; parents read and played in a more stimulating manner and reported being less tired and miserable. Nevertheless, structured support generally requires more training and supervision, and while it may appeal to some families, it has been suggested that many mothers may respond better to support that is more flexible and acknowledge their own expertise $[27,28]$ which may be easier for a lay visitor.

Home-Start support is offered widely in the UK and provides visits by local volunteer parents who receive some preparation about how to be supportive but generally decide on the content of visits and their frequency with the family [29]. Several uncontrolled studies of Home-Start suggest that it is valued by families, who believe that it has beneficial impacts [30-32]. However, one quasiexperimental study did not find a significant difference between those receiving Home-Start support and those receiving standard local services in either the outcomes examined or the extent to which services other than Home-Start were used [33]. A second cluster-randomised trial studying families with new infants found only one impact of Home-Start support on parenting; reports of parental stress were lower when infants were 12 months old compared to two months, a greater decrease than was found for control families [34]. However, no impact of the support was found over the same time period on the alleviation of maternal depression or of new cases developing [35]. While volunteer home visiting may seem to be an attractive policy for supporting families, given its relatively low cost, it has been emphasised that commissioners of services should focus on programmes that are committed to continuous quality improvement as well as rigorous evaluations of efficacy [36]. Volunteer home visiting may be low in cost, but the majority of the evidence for its positive impact is anecdotal rather than from controlled studies. This study was designed to determine if volunteer support offered prior to or soon after an infant's birth could have a positive impact on child development when infants were 12 months of age.

\section{Method}

Ethical approval was obtained from the NHS Multi-Centre Research Ethics Committee (MREC) and all relevant local Research Ethics Committees.

\subsection{Procedure}

2.1.1. Home-Start Schemes. The Home-Start national organisation agreed to participate in the study only if randomisation was at the scheme level and only if research home visits 
were initiated after the home visiting had been established and the families had been given time to settle into a routine following the birth of their new babies. Of 237 Home-Start schemes in England, at the time $161(68 \%)$ were eligible and approached, and $41(24 \%)$ agreed to be randomised. Ineligibility was because their catchment area was also a Sure Start Local Programme area $(n=15)$; (Sure Start Local Programmes was a national area-based government intervention designed to strengthen and add to services for families with children from 0 to 3 . One of the six core services offered in all areas was home visiting to all mothers with a new baby, though the amount of home visiting and the nature of the visitor varied though the country). Home-Start judged that they were not ready for involvement in research $(n=20)$, or they were already offering proactive support for new mothers in their area $(n=7)$. A further 34 were excluded for logistic reasons (too distant). The initial randomization for schemes was $1: 1$, but insufficient schemes volunteered to meet the target of 50 , so randomization was changed to $2: 1$ part-way through. The final distribution was 24 intervention and 17 control schemes. Each intervention scheme received a payment of $£ 500$ to cover the costs of preparing new volunteers.

2.1.2. Families. Recruitment took place in waiting areas during routine antenatal clinics. Mothers were told that the study was designed to find out if offering homevisiting volunteer support to families made a difference. All completed a brief screening measure to determine eligibility and gave initial consent so that they could be contacted once their infant was born. They were told that further contact from the researchers, when their infants were 2 months and 12 months of age, would depend on background characteristics collected at recruitment. In areas randomised to provide the intervention, women were also told that they might be contacted by Home-Start before their baby was born to offer volunteer support; those in the control areas were told that the support was not available in their area.

Eligibility criteria for inclusion were living in the geographical areas covered by the Home-Start scheme; mother at least 18 years; able to understand spoken English; infant birth weight $\geq 2500$ grams; $\leq 5$ days in Special Care Baby Unit; a score of 9 or more on a modified version of the social disadvantage screening index (SDI) [37] with a range from 0 to 21. The SDI includes highest occupation of either partner; highest educational qualification of either partner; tenure of accommodation; overcrowding; accommodation shared or not; availability of a vehicle; type of neighbourhood, based on the Jarman Underprivileged Area Score [38].

2.2. Participants. In pregnancy, 1,007 mothers-to-be agreed to be involved, 541 in intervention neighbourhoods, and 466 in control neighbourhoods. Just over half the families in intervention and control areas were eligible (intervention areas 274/541, 51\%; control areas 253/466, 54\%). The mean SDI of eligible families in the intervention areas was higher than that of the families in control areas (mean SDI: intervention 11.3, s.d. 1.9; control 10.9, s.d. 1.8; $t=2.22, P<$ $.05)$.
Names and contact details of eligible families in the intervention areas were passed to their local Home-Start scheme. Of the 274 eligible intervention families, 96 received HomeStart support, defined as more than one visit while $178 \mathrm{did}$ not. Of the 178 unsupported intervention families, three quarters declined the offer either following telephone contact by Home-Start $(73,41 \%)$ or after the initial visit by the Home-Start scheme coordinator $(60,34 \%)$ [39]. Some (29, $16 \%)$ were never contacted by Home-Start, and a small number accepted the offer and were either put on a waiting list but never given a volunteer $(10,6 \%)$ or received only one support visit $(6,3 \%)$. Those not receiving the support had a significantly higher mean SDI score than the supported families (not supported $N=178,11.5$; received support $N=96,11.0, t=2.73, P<.05$; see Figure 1$)$. All but one of the supported families $(N=95)$ received a research visit when their infant was 2 months old, 93 received a visit when their infant was 12 months old, and 92 received both.

The extent to which families in the Home-Start areas were not receiving the service only became evident part-way through the study, and contact was then made with unsupported intervention families to gain their agreement for research visits. It was possible to contact 130 and 97 (75\%) agreed. For some, their infants were older than 2 months, but the 2-month home visits were completed for 73 and 90 had a visit when their infants were 12 months of age, with completed visits at both time points for 66 (see Figure 1).

Just over three quarters (196/253, 77\%) of eligible families recruited in the control areas agreed to research visit when recontacted after their child's birth. Those who did not agree $(N=57)$ had a significantly higher mean SDI than those families taking part in the research (declined: 11.8, took part: $10.7, t=4.14, P<.001$; see Figure 1 ). All but one (195) of the participating families received a research visit when their infant was 2 months old, and 179 were visited when their infant was 12 months old, 178 receiving both research visits.

Detailed information about family demographics, child, and family characteristics was collected during two research home visits completed when infants were 2 and 12 months of age. Thus, there is little true "baseline" information apart from general family vulnerability. A $\mathfrak{E} 10$ shopping voucher was given at the end of each research home visit. These were conducted blind to whether the area was one in which families were offered Home-Start support or areas where no support had been offered.

2.3. The Intervention. Home-Start offers a service intended to complement the role of professionals by improving the support available to families who may not want or be identified as requiring on-going professional help. Emphasising the befriending nature of the support, volunteers are mainly parents themselves who aim to remove any stigma attached to receiving help, responding to families with flexibility, openness, and encouragement so that parents' capacity to cope is enhanced. There are national guidelines for volunteer preparation and general guidelines about the nature of the support offered to families [29]. Preparation consists of 10 


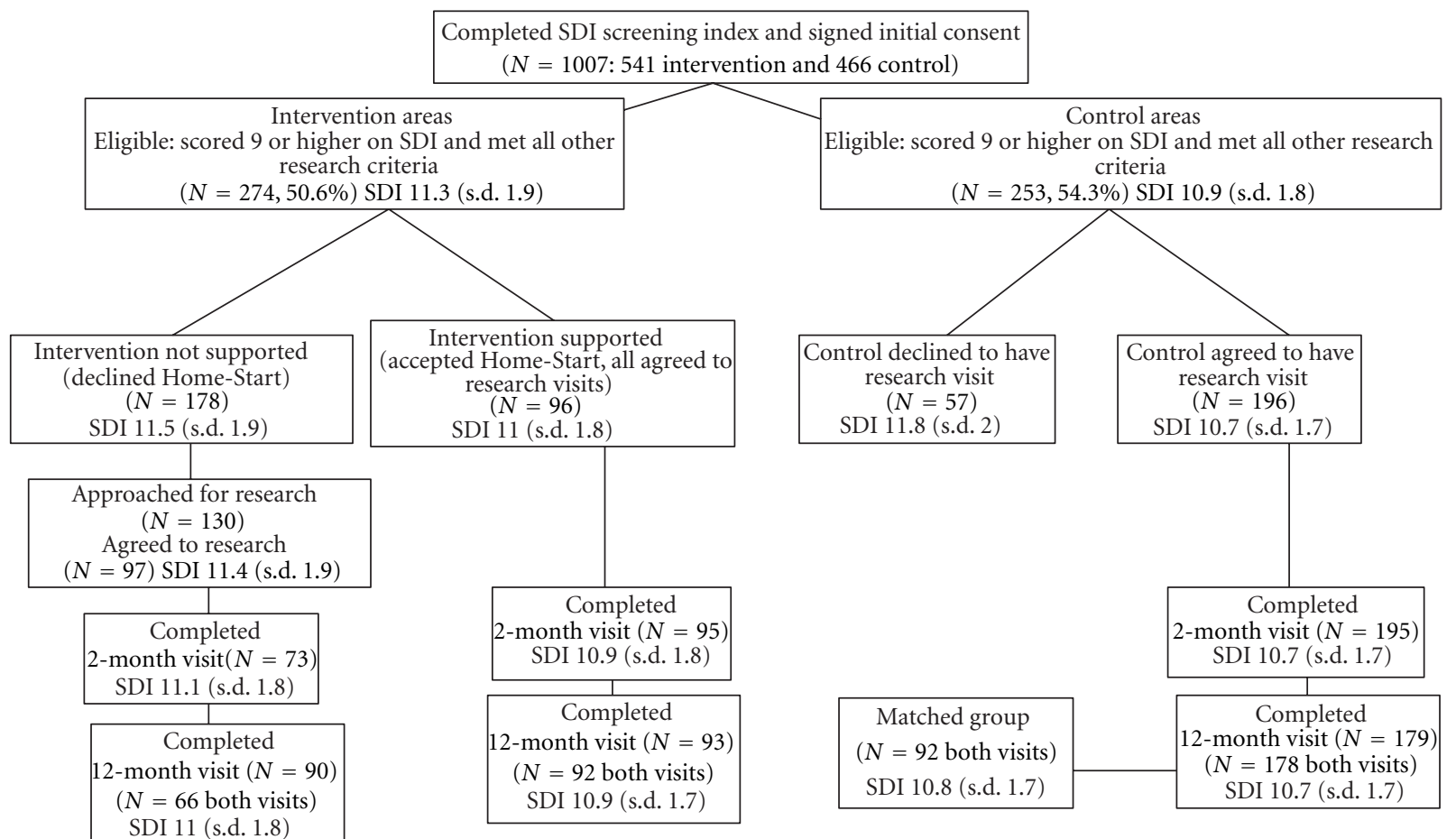

Figure 1: Consort diagram. Notes: recruitment was in pregnancy. Research visits took place in homes when infants were 2 months old and 12 months old. SDI = social disadvantage index [37]. Significant differences identified in SDI mean scores. Total eligible intervention group (mean SDI 11.3, $N=274$ ) > total eligible control group (mean SDI 10.9, $N=253$ ); $t=2.22, P<.05$. Total not supported group (mean SDI $11.5, N=178)>$ total control group (mean SDI $=10.7, N=196) ; t=2.53, P<.05$. Total not supported group (mean SDI $11.5, N=178)$ $>$ total supported group (mean SDI 11.0, $N=96) ; t=2.73, P<.05$. Control group declining research $($ mean SDI $11.8, N=57)>$ control group taking part (mean SDI 10.7, $N=196) ; t=4.14, P<.001$.

half-day sessions covering topics such as safety when working in homes, how to be nonjudgemental, how to find out what the needs of the family are, and how to deal with safeguarding issues. Two additional training sessions were created for the study to cover issues and topics particularly relevant for families with a new baby (see [34] for more details).

After an initial visit from the local Home-Start scheme coordinator to decide if the family wanted support and to discuss their needs, a volunteer was identified matched as closely as possible to the family. Subsequently, volunteers and families jointly decided on needs, on the frequency of visits, and how long the support should continue. They may engage in a number of different activities, providing company, assistance with childcare or other household tasks, going out on joint trips to local facilities, or giving parenting advice (see [40] for details).

Families in the control group and those in intervention areas offered but not receiving Home-Start received existing services provided by the UK National Health Service (NHS) free of charge to all mothers and infants, that is, home visits from a midwife are routine during pregnancy, and for two weeks after the birth, home visits are routine from a health visitor after the child's birth; there is on-going availability of their general practitioner (GP) and, when referred by the GP, from any of the specialist mental health services [41].

\subsection{Measures}

2.4.1. Maternal Depression. Maternal depression symptoms in the previous seven days were assessed with the Edinburgh Postnatal Depression Scale (EPDS), [42] when infants were 2 and 12 months old. This 10-item self-report questionnaire was developed for use by primary care health workers to screen and identify postnatal depression. Items are scored 0 to 3 , with a cutoff of 13 or more indicating depression. Its internal consistency with this sample was high $(\alpha=0.87)$.

2.4.2. Family Stress. The parenting stress index short form (PSI/SF, 36 items; [43]) was administered when infants were 2 and 12 months of age. Responses to 36 statements are on a five-point scale from strongly agree to strongly disagree, with scores ranging from 36 to 180 (Cronbach $\alpha: 2 \mathrm{~m} ., 0.92 ; 12 \mathrm{~m}$., $0.99)$. Questions cover three domains, each with 12 items: parental distress (e.g., "I feel alone and without friends"); parent-child dysfunctional interaction (e.g., "My baby smiles at me much less than I expected"); difficult child (e.g., "My baby makes more demands on me than most babies").

2.4.3. Parenting and the Home Environment. The Infant/ Toddler version of the Home observation for measurement of the environment (HOME) inventory [44] was administered when infants were 2 and 12 months old. This standardised assessment is designed to provide an understanding of 
the child's experience completed through a semistructured conversation with the primary caregiver in the home with the child present and consists of 45 items (scored either 1 "yes" or 0 "no"). A total score is calculated, with a higher score indicating a more advantageous home environment for child development (Cronbach $\alpha: 2$ m., 0.80; 12 m., 0.76). Reliability was established between six raters, with Kappas ranging from 0.76 to 0.94 , mean 0.86 .

2.4.4. Infant Temperament. Infant difficult temperament was measured when infants were 2 and 12 months old using the Infant Characteristics Questionnaire (ICQ) [45]. The ICQ asks a parent to describe their baby's characteristics using seven-point Likert scales, in response to questions about day-to-day behaviour. A mean item score of 1 indicates a favourable temperament, whereas a score of 7 indicates difficult temperament.

2.4.5. Infant Cognitive Development. The Bayley Scales of Infant Development [46], a widely used standardised assessment of infants' cognitive, language, and social/behavioural development, was administered when infants were 12 months of age. It has three scales: the mental development index (MDI); behaviour; motor development, but only the MDI was used in this study. Researchers received extensive training in the Bayley administration and strictly adhered to the procedures as detailed in the manual. Inter-rater reliability for the research team's scoring was calculated using Cohen's Kappa, and scores ranged from 0.75 to 0.96 (mean $0.84)$.

2.5. Statistical Analysis. Only those families with complete data when infants were both 2 and 12 months of age were included in analyses. Using SPSS version, 18 comparisons were made between the Home-Start-supported group and both comparison groups (matched control group, unsupported intervention group) of their SDI scores, demographic characteristics, and all characteristics assessed at 2 and 12 months, using chi-square for categorical variables and $t$-tests for continuous variables. Pearson correlation coefficients were calculated between child and family characteristics and the Bayley Mental Developmental Index (MDI) to determine which variables should be entered into multiple regressions to identify significant predictors of child developmental status at 12 months of age. After controlling for these characteristics, group membership was entered, comparing supported families with matched control families and comparing supported families with others in the same areas who did not receive Home-Start support.

\section{Results}

3.1. Receipt of Support. Families were referred to Home-Start during pregnancy, but there was a substantial range in the average age in which the support started, reflecting different local capacity and the availability of suitable volunteers. On average, support started just after birth at 0.2 months (s.d.
1.7 months), but this ranged from three months before the infant's birth to 4 months after the birth. More than half of the support $(56 \%)$ had started by the infant's birth, and almost all families (93\%) were receiving support when the first research home visit was made and when infants were 2 months old meaning that the family characteristics such as reported stress, the home environment, and maternal depression and child characteristics such as difficult temperament may have been influenced by the support. The frequency and duration of support were determined by the volunteer and family jointly, and the research team could not influence this. Support did not extend through the whole first year for most families, the average number of visits was 15.1 (s.d. 11.9, range from 2 to 50), and average of months of support was 5.5 (s.d. 3.6, range from 1 to 14).

3.2. Demographic and Family Characteristics. Given the difference in mean SDI scores between the total intervention and control groups, the scores of families taking part in the research visits were compared, and there was only one difference. The total control group $(N=196)$ had a lower mean SDI (10.7, s.d. 1.7) than the group that was offered but did not receive Home-Start support and that agreed to research visits (11.2, s.d. 1.8; $N=97$; see Figure 1$)$. There was no significant difference in mean SDI scores between the families who received Home-Start (11.0, s.d. $1.8 ; N=96)$ and the total control group $(10.7$, s.d. $1.7 ; N=196)$ or between the Home-Start-supported group and the group declining support (11.2, s.d. $1.8 ; N=97)$. Nor were there any significant differences in SDI scores between the three groups included in the final analyses, all of whom had completed both research visits and including only the matched control group (not supported 11.0, s.d. 1.8; $N=66$; supported 10.9 , s.d. $1.7 ; N=92$; controls 10.6 , s.d. $1.7 ; N=92$; see Figure 1).

The mean SDI of the intervention group families supported by Home-Start and completing both research visits $(N=92)$ did not differ significantly from the mean SDI for the control group with both research visits $(N=178)$ or the unsupported intervention group $(N=66$; see Figure 1). However, comparisons of demographic characteristics that contributed to the SDI revealed some differences between the supported group and the total control group $(N=$ 178) (see Table 1). On average, the supported mothers had more children and more educational qualifications, fewer were in employment, and fewer were white. Rather than controlling for these characteristics in a multiple regression, it was decided to create a smaller matched control group of 92 to compare with the 92 mothers in the supported group seen when infants were 2 and 12 months. They were matched on the number of children in the family, maternal occupational status, maternal educational qualifications, and maternal ethnic background (white/nonwhite). This matched group did not differ from the intervention-supported group in their demographic characteristics (see Table 1). The unsupported families in intervention areas $(N=66)$ did not differ significantly from the supported families $(N=92$, see Table 1). 
TABLE 1: Comparisons between groups in demographic characteristics of families seen at both research visits, when infants were 2 and 12 months of age (standard deviations or percentages in brackets).

\begin{tabular}{|c|c|c|c|c|}
\hline & $\begin{array}{c}\text { Intervention group: } \\
\text { supported } \\
N=92 \\
\end{array}$ & $\begin{array}{c}\text { Intervention group: } \\
\text { not supported } \\
N=66 \\
\end{array}$ & $\begin{array}{l}\text { Total control group } \\
\qquad N=178\end{array}$ & $\begin{array}{l}\text { Matched control group } \\
\qquad N=92\end{array}$ \\
\hline Mean maternal age (years) & $29.0(5.7)$ & $28.6(5.9)$ & $28.1(6.1)$ & $29.0(5.8)$ \\
\hline $\begin{array}{l}\text { Mean number of children in family } \\
\text { (including new baby) }^{1}\end{array}$ & $2.3(1.1)$ & $2.2(1.3)$ & $2.1(1.1)$ & $2.1(0.8)$ \\
\hline New baby male & $48(52.2)$ & $35(53.0)$ & $87(48.9)$ & $47(51.1)$ \\
\hline Biological father in the home & $73(79.3)$ & $51(77.3)$ & $142(79.8)$ & $76(82.6)$ \\
\hline Mother white ${ }^{2}$ & $76(82.6)$ & $48(72.7)$ & $161(90.4)$ & $79(85.9)$ \\
\hline \multicolumn{5}{|l|}{ Family structure } \\
\hline Mother single & $17(18.5)$ & $13(19.7)$ & $30(16.9)$ & $13(14.1)$ \\
\hline Living with partner & $27(29.3)$ & $22(33.3)$ & $71(39.9)$ & $40(43.5)$ \\
\hline Married & $48(52.2)$ & $31(47.0)$ & $77(43.3)$ & $39(42.4)$ \\
\hline \multicolumn{5}{|l|}{ Mother's highest qualification ${ }^{3}$} \\
\hline Degree/higher degree & $19(20.7)$ & $7(10.6)$ & $10(5.6)$ & $10(10.9)$ \\
\hline Advanced level (age 18) & $8(8.9)$ & $5(7.6)$ & $22(12.4)$ & $11(12.0)$ \\
\hline $\begin{array}{l}\text { General certificate of secondary education } \\
\text { (age 16) }\end{array}$ & $26(28.3)$ & $19(28.0)$ & $65(36.5)$ & $26(28.3)$ \\
\hline Other qualification & $32(34.8)$ & $28(42.4)$ & $63(35.4)$ & $38(41.3)$ \\
\hline None & $7(7.6)$ & $7(10.6)$ & $18(10.1)$ & $7(7.6)$ \\
\hline \multicolumn{5}{|l|}{ Mother's occupation ${ }^{4}$} \\
\hline Professional & $9(9.8)$ & $4(6.1)$ & $17(9.6)$ & $10(10.9)$ \\
\hline Intermediate/small employer & $17(18.5)$ & $14(21.2)$ & $41(23.0)$ & $21(22.8)$ \\
\hline $\begin{array}{l}\text { Lower supervisory/technical/semiroutine/ } \\
\text { routine }\end{array}$ & $21(22.8)$ & $24(36.4)$ & $63(35.4)$ & $19(20.7)$ \\
\hline Unemployed or student & $45(48.9)$ & $24(36.4)$ & $57(32.0)$ & $42(45.7)$ \\
\hline \multicolumn{5}{|l|}{ Father's highest qualification } \\
\hline Degree/higher degree & $14(17.7)$ & $7(13.7)$ & $11(6.8)$ & $8(9.5)$ \\
\hline Advanced level (age 18) & $7(8.9)$ & $4(7.8)$ & $16(9.9)$ & $11(13.1)$ \\
\hline $\begin{array}{l}\text { General certificate of secondary education } \\
\text { (age 16) }\end{array}$ & $28(35.4)$ & $18(35.3)$ & $65(40.4)$ & $34(40.5)$ \\
\hline Other qualification & $18(22.8)$ & $18(35.3)$ & $48(29.8)$ & $25(29.8)$ \\
\hline None & $12(15.2)$ & $4(7.8)$ & $21(13.0)$ & $6(7.1)$ \\
\hline \multicolumn{5}{|l|}{ Father's occupation } \\
\hline Professional & $9(10.8)$ & $6(10.2)$ & $11(6.7)$ & $5(5.8)$ \\
\hline Intermediate/small employer & $21(25.3)$ & $10(16.9)$ & $32(19.4)$ & $21(24.4)$ \\
\hline $\begin{array}{l}\text { Lower supervisory/technical/semiroutine/ } \\
\text { routine }\end{array}$ & $43(51.8)$ & $37(62.7)$ & $107(64.8)$ & $52(60.5)$ \\
\hline Unemployed or student & $10(12.0)$ & $6(10.2)$ & $15(9.1)$ & $8(9.3)$ \\
\hline
\end{tabular}

${ }^{1}$ Mean higher for intervention supported group $(n=92)$ versus total control group $(N=178), t=1.80, P=.07$.

${ }^{2}$ Proportion lower in intervention-supported group $(N=92)$ versus total control group $(N=178)$, chi-square $3.476,1 \mathrm{df}, P=.06$.

${ }^{3}$ Significant difference between intervention-supported group $(N=92)$ and total control group $(N=178)$, chi-square $15.73,4 \mathrm{df}, P<.01$.

${ }^{4}$ Significant difference between intervention-supported group $(N=92)$ and total control group $(N=178)$, chi-square $8.25,3 \mathrm{df}, P<.05$.

Comparisons of child and family characteristics indicated that, despite matching, there was one difference between the supported group and the matched controls, with intervention mothers reporting more parenting stress when their infants were 2 months old than the matched controls. Consequently, this was controlled for in regression analyses, as these were all other indicators with significant correlation coefficients with the Bayley MDI (see Table 2).

3.3. Child Cognitive Development. In uncontrolled comparisons, infants in the matched control group had a significantly higher mean Bayley MDI score than the children 
TABLE 2: Comparisons between groups in mean characteristics of the children, mothers, and the home environment of families seen at both research visits, when infants were 2 and 12 months of age (standard deviations or percentages in brackets).

\begin{tabular}{|c|c|c|c|c|c|c|}
\hline & $\begin{array}{c}\text { Correlation } \\
\text { coefficient with } \\
\text { 12-month Bayley } \\
\text { MDI } \\
N=250\end{array}$ & $\begin{array}{c}\text { Intervention } \\
\text { group: supported } \\
\text { mean } \\
N=92\end{array}$ & $\begin{array}{l}\text { Intervention } \\
\text { group: not } \\
\text { supported mean } \\
\quad N=66\end{array}$ & $\begin{array}{l}\text { Matched control } \\
\text { group mean } \\
\quad N=92\end{array}$ & $\begin{array}{c}\text { Intervention } \\
\text { supported versus } \\
\text { intervention not } \\
\text { supported }\end{array}$ & $\begin{array}{l}\text { Intervention- } \\
\text { supported versus } \\
\text { matched controls }\end{array}$ \\
\hline \multicolumn{7}{|c|}{ Infant 2 months old } \\
\hline $\begin{array}{l}\text { Mean maternal } \\
\text { depression }(\text { EPDS })^{1}\end{array}$ & $-.14^{*}$ & $8.2(5.8)$ & $7.9(5.7)$ & $6.8(4.9)$ & $t=.33$ n.s. & $t=1.84$ n.s. \\
\hline $\begin{array}{l}\text { Mean parenting } \\
\text { distress }(\mathrm{PSI})^{2}\end{array}$ & $-.22^{* *}$ & $72.6(16.4)$ & $70.8(15.9)$ & $67.5(15.6)$ & $t=.75$ n.s. & $\begin{array}{c}t=2.14 \\
P<.05\end{array}$ \\
\hline $\begin{array}{l}\text { Mean } \mathrm{HOME}^{3} \\
\text { environment }\end{array}$ & $.14^{*}$ & $32.3(5.1)$ & $31.8(5.5)$ & $33.2(5.6)$ & $t=.63 \mathrm{n} . \mathrm{s}$ & $t=-1.09$ n.s. \\
\hline $\begin{array}{l}\text { Mean child difficult } \\
\text { temperament (ICQ) }\end{array}$ & $-.15^{*}$ & $2.9(.76)$ & $2.7(.78)$ & $2.7(.72)$ & $t=.83$ n.s. & $t=1.13$ n.s. \\
\hline \multicolumn{7}{|c|}{ Infant 12 months old } \\
\hline $\begin{array}{l}\text { Mean maternal } \\
\text { depression (EPDS) }\end{array}$ & -.08 & $7.0(5.9)$ & $6.8(5.0)$ & $6.3(5.4)$ & $t=.19$ n.s. & $t=.77$ n.s. \\
\hline $\begin{array}{l}\text { Mean parenting } \\
\text { distress (PSI) }\end{array}$ & $-.16^{*}$ & $66.5(14.4)$ & $66.9(15.6)$ & $66.9(17.7)$ & $t=.62$ n.s. & $t=-.16$ n.s. \\
\hline $\begin{array}{l}\text { Mean HOME } \\
\text { environment }\end{array}$ & $.33^{* *}$ & $38.4(5.0)$ & $38.3(4.5)$ & $39.6(3.9)$ & $t=.13$ n.s. & $t=-1.78$ n.s. \\
\hline $\begin{array}{l}\text { Mean child difficult } \\
\text { temperament (ICQ) }\end{array}$ & -.07 & $2.8(.73)$ & $2.9(.68)$ & $2.8(.64)$ & $t=-.10$ n.s. & $t=.78$ n.s. \\
\hline
\end{tabular}

${ }^{*}$ Correlation coefficient is significant at $P<.05,{ }^{* *}$ correlation coefficient is significant at $P<.01$.

${ }^{1}$ Edinburgh postnatal depression scale [42].

${ }^{2}$ Parenting stress index [43].

${ }^{3}$ Home observation for measurement of the environment [44].

${ }^{4}$ Infant characteristics questionnaire [45].

TABle 3: Results of multiple regression to predict the Bayley Mental Developmental Index, comparing Home-Start-supported families and matched controls.

\begin{tabular}{|c|c|c|c|c|c|}
\hline & \multicolumn{2}{|c|}{ Unstandardized coefficients } & \multirow{2}{*}{$\begin{array}{c}\text { Standardized coefficients } \\
\text { Beta }\end{array}$} & \multirow{2}{*}{$t$} & \multirow{2}{*}{ Sig. } \\
\hline & $B$ & Std. error & & & \\
\hline EPDS $^{1}$ total score 2 months & .076 & .181 & .037 & .422 & .674 \\
\hline PSI $^{2}$ total score 2 months & -.149 & .073 & -.215 & -2.049 & .042 \\
\hline $\mathrm{HOME}^{3}$ total score 2 months & -.199 & .179 & -.095 & -1.112 & .268 \\
\hline $\mathrm{ICQ}^{4}$ mean item score 2 months & -.092 & 1.262 & -.006 & -.073 & .942 \\
\hline HOME total score 12 months & .785 & .208 & .312 & 3.779 & .000 \\
\hline PSI total score 12 months & -.025 & .060 & -.036 & -.420 & .675 \\
\hline Matched control group & 2.656 & 1.584 & .119 & 1.677 & .095 \\
\hline
\end{tabular}

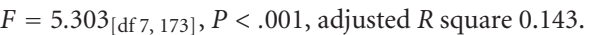

${ }^{1}$ Edinburgh postnatal depression scale [42].

${ }^{2}$ Parenting stress index [43].

${ }^{3}$ Home observation for measurement of the environment [44].

${ }^{4}$ Infant characteristics questionnaire [45].

in families supported by Home-Start (mean MDI: control group 93.3, s.d. 10.9; supported group 89.0, s.d. 11.2; $t=$ $2.59, P<.01)$. In uncontrolled comparisons, infants in the intervention areas whose families were not supported did not differ significantly from infants whose families received Home-Start supported, though the trend was in a similar direction to the results comparing the supported families with the matched controls, a higher mean Bayley MDI for the unsupported group (not supported 92.2, s.d. 9.3; supported group 89.0 , s.d. $11.2 ; t=1.84, P=.07$ ).

Multiple regression analyses were conducted first to include the supported and matched controls and then the supported and nonsupported families from the intervention areas, taking into account all 2- and 12-month characteristics significantly associated with the Bayley MDI (see Tables 3 and 4). Home-Start support, compared to being in the matched 
TABLE 4: Results of multiple regression to predict the Bayley Mental Developmental Index, comparing Home-Start-supported families and intervention area families not receiving support.

\begin{tabular}{|c|c|c|c|c|c|}
\hline & \multicolumn{2}{|c|}{ Unstandardized coefficients } & \multirow{2}{*}{$\begin{array}{c}\text { Standardized coefficients } \\
\text { Beta }\end{array}$} & \multirow{2}{*}{$t$} & \multirow{2}{*}{ Sig. } \\
\hline & B & Std. error & & & \\
\hline EPDS $^{1}$ total score 2 months & .171 & .176 & .093 & .973 & .332 \\
\hline $\mathrm{PSI}^{2}$ total score 2 months & .019 & .077 & .029 & .244 & .808 \\
\hline $\mathrm{HOME}^{3}$ total score 2 months & -.194 & .206 & -.094 & -.939 & .349 \\
\hline $\mathrm{ICQ}^{4}$ mean item score 2 months & -1.369 & 1.211 & -.100 & -1.130 & .260 \\
\hline HOME total score 12 months & .874 & .205 & .398 & 4.267 & .000 \\
\hline PSI total score 12 months & -.122 & .074 & -.168 & -1.662 & .099 \\
\hline Intervention, not supported & 2.998 & 1.669 & .138 & 1.796 & .075 \\
\hline
\end{tabular}

$F=4.311_{[\mathrm{df} 7,141]}, P<.001$, adjusted $R$ square 0.135 .

${ }^{1}$ Edinburgh postnatal depression scale [42].

${ }^{2}$ Parenting stress index [43].

${ }^{3}$ Home observation for measurement of the environment [44].

${ }^{4}$ Infant characteristics questionnaire [45].

control group, was not a significant predictor of the Bayley MDI. Children were likely to have higher MDI scores when mothers reported less parenting stress at 2 months and when the home environment was rated as more stimulating and responsive at 12 months (see Table 3). Home Start support, compared to being in the same areas but not receiving the support, was not a significant predictor of the Bayley MDI, with a more stimulating and responsive home environment at 12 months as the only significant predictor (see Table 4).

3.4. Discussion. This study reflects a challenge that faces many researchers to attempt a rigorous study design in a realworld setting. The intervention providers imposed restrictions which weakened the study. Cluster randomisation of areas rather than families led to a control group that was less vulnerable based on the screening instrument. Possibly in the intervention areas, more families with some problems thought that taking part in the study would be a good idea, whereas in the control areas, they would not receive support, so this was not a factor influencing involvement. A trial with randomisation of families within each area would have been preferable. However, the eventual supported and control groups receiving both research visits did not have significantly different scores on the screening instrument, principally because the most vulnerable of the control group families declined to take part in the research. A second issue was the low rate at which the support was taken up by families whose names had been passed to Home-Start organisers, which was probably a reflection of the fact that this study referred families to them based on risk factors, whereas their more usual practice was to receive referrals of families with identifiable problems. Nevertheless, once this issue came to the research team's notice, a second "no treatment" control group could be included which proved useful since they did not differ from the supported group in any way.

A further restriction imposed by the voluntary organisation was that research visits should not start until families had become "settled" following their new baby's birth, with two months of age being the agreed first research contact. This information then could not be considered a baseline since for almost all the supported families visits had been initiated, some several months earlier and before the birth. Supported families reported experiencing more stress in their parenting at that first visit than the control families. This could mean that the matching failed to take into account sufficient factors and that they did have more stress, despite similar demographic characteristics. There may also be other aspects of the families that the study did not measure. The families who agreed to the support may have been hoping to meet someone who could share their problems and have had greater concern about their ability to cope with their infants. It could also mean that the introduction of a volunteer had led them to talk about and contemplate their difficulties more openly as a first stage of dealing with them, so they were more likely to report problems on a questionnaire. This might be the case since the only impact of the support on parenting identified for these families was that the parenting stress reported by mothers in the supported group started higher but was reduced significantly more than the stress reported by the control group [34].

The level of parenting stress reported at two months was a significant predictor of a lower MDI score when infants were 12 months old, but receipt of support was not significant. Perceiving parenting as stressful when infants are in their first few weeks may leave mothers less able to be responsive and stimulating, and it was this aspect of the home environment when infants were 12 months of age that was a significant predictor of Bayley MDI scores in both regression analyses. This suggests that home visiting, whether from a volunteer or from a professional, may be more effective in promoting child development if parents are given strategies to enable them to be more responsive, focussing on promoting positive parent-child interactions rather than concentrating on stress. A qualitative study exploring the nature of Home-Start support [40] concluded that the volunteers primarily provided emotional support. While sharing problems, which did lead to less perceived stress over the year, is beneficial to the mother which may mean that there is a less focus on activities likely to stimulate infants. 
This study did not show that volunteer support of an indeterminate nature offered proactively in pregnancy was likely to enhance child cognitive development at the end of the child's first year, and this appears to be a reasonable robust result, despite the study limitations since it was shown with two different comparison groups. In addition, it reflects the findings of the only other randomised study of this particular volunteer support which found no impact on children's socioemotional development [33]. Null findings can be as important as evidence that interventions can have an impact so that resources can be directed effectively.

To enhance child cognitive development, it is probably necessary either to intervene directly with children or to work with parents specifically on ways to promote infant development, as occurs in the Nurse Family Partnership programme $[20,22]$ to make any substantial impact. Volunteer support has its place, and many qualitative studies have identified the value that parents place on this kind of input and gain emotional sustenance [30,31, 40]. However, if a child is at risk of poor cognitive development, the provision of home-based volunteer support is likely to be useful only if volunteers follow a theoretically driven strategy, over a set number of visits and with a range of materials. Alternatively the involvement of volunteers may be an important way to introduce the family to other professional services designed specifically to promote child development.

\section{Acknowledgments}

The study was funded by a Grant from the Health Foundation (no. 16665/608) awarded to the author as a Principal Investigator and to Dr. Rob Senior as a Coinvestigator. The study would not have been possible without the close cooperation and involvement of the Home-Start national office, the local Home-Start schemes, and the many professionals throughout the country in antenatal and well-baby clinics who assisted with the recruitment. In addition, the study would not have been possible without the families who took time to welcome the researchers into their homes and talked openly about their lives and families. Thanks are also due to the dedicated research team who conducted the interviews, with particular thanks to Dr. Kristen MacPherson for coordinating the trial.

\section{References}

[1] B. D. Perry, "Childhood traumas and the neurobiology of adaptation and the dependent development of the brain: how states become traits," Infant Mental Health Journal, vol. 16, no. 4, pp. 271-291, 1995.

[2] R. Shore, Re-Thinking the Brain: New Insights Into Early Development, Families \& Work Institute, New York, NY, USA, 1997.

[3] J. M. Love, E. E. Kisker, C. M. Ross et al., Making a Difference in the Lives of Infants and Toddlers and Their Families: The Impacts of Early Head Start, US Department of Health and Human Services, Administration for Children and Families, Head Start Bureau, Washington, DC, USA, 2002.
[4] G. Allen, Early Intervention: The Next Steps, HM Government Cabinet Office, London, UK, 2011.

[5] J. Barnes and A. Freude-Lagevardi, From Pregnancy to Early Childhood: Early Interventions to Enhance the Mental Health of Children and Families, Mental Health Foundation, London, UK, 2003.

[6] P. L. Engle, L. C. H. Fernald, H. Alderman et al., "Strategies for reducing inequalities and improving developmental outcomes for young children in low-income and middle-income countries," The Lancet, vol. 378, no. 9799, pp. 1339-1353, 2011.

[7] J. J. Heckman, "Skill formation and the economics of investing in disadvantaged children," Science, vol. 312, no. 5782, pp. 1900-1902, 2006.

[8] E. C. Melhuish, A Literature Review of the Impact of Early Years Provision Upon Young Children, National Audit Office, London, UK, 2004.

[9] C. T. Ramey and S. L. Ramey, "Prevention of intellectual disabilities: early interventions to improve cognitive development," Preventive Medicine, vol. 27, no. 2, pp. 224-232, 1998.

[10] L. J. Schweinhart and D. P. Weikart, "The high/scope preschool curriculum comparison study through age 23," Cognitive Development, vol. 12, no. 2, pp. 117-143, 1997.

[11] J. MacLeod and G. Nelson, "Programs for the promotion of family wellness and the prevention of child maltreatment: a meta-analytic review," Child Abuse and Neglect, vol. 24, no. 9, pp. 1127-1149, 2000.

[12] Infant Health and Development Program (IHDP), "Enhancing the outcomes of low-birth-weight, premature infants," Journal of the American Medical Association, vol. 263, no. 22, pp. 3035-3042, 1990.

[13] J. McGuire and F. Earls, "Prevention of psychiatric disorders in early childhood," Journal of Child Psychology and Psychiatry and Allied Disciplines, vol. 32, no. 1, pp. 129-154, 1991.

[14] J. Barnes, "Interventions addressing infant mental health problems," Children and Society, vol. 17, no. 5, pp. 386-395, 2003.

[15] D. Kendrick, R. Elkan, M. Hewitt et al., "Does home visiting improve parenting and the quality of the home environment? A systematic review and meta analysis," Archives of Disease in Childhood, vol. 82, no. 6, pp. 443-451, 2000.

[16] E. D. Hodnett and I. Roberts, "Home-based social support for socially disadvantaged mothers," Cochrane Database of Systematic Reviews, no. 2, p. CD000107, 2000.

[17] P. Moran, D. Ghate, and A. ven der Merwe, What Works in Parenting Support? Department for Education and Skills, London, UK, 2004.

[18] D. L. Olds, L. Sadler, and H. Kitzman, "Programs for parents of infants and toddlers: recent evidence from randomized trials," Journal of Child Psychology and Psychiatry and Allied Disciplines, vol. 48, no. 3-4, pp. 355-391, 2007.

[19] R. Edwards and V. Gillies, "Support in parenting: values and consensus concerning who to turn to," Journal of Social Policy, vol. 33, no. 4, pp. 627-647, 2004.

[20] D. L. Olds, “The nurse-family partnership: an evidence-based preventive intervention," Infant Mental Health Journal, vol. 27, no. 1, pp. 5-25, 2006.

[21] D. L. Olds, C. R. Henderson, R. Chamberlin, and R. Tatelbaum, "Preventing child abuse and neglect: a randomized trial of nurse home visitation," Pediatrics, vol. 78, no. 1, pp. 65-78, 1986.

[22] D. L. Olds, J. Robinson, R. O’Brien et al., "Home visiting by paraprofessionals and by nurses: a randomized, controlled trial," Pediatrics, vol. 110, no. 3, pp. 486-496, 2002. 
[23] A. Oakley, L. Rajan, and A. Grant, "Social support and pregnancy outcome," British Journal of Obstetrics and Gynaecology, vol. 97, no. 2, pp. 155-162, 1990.

[24] M. O. Marcenko and M. Spence, "Home visitation services for at-risk pregnant and postpartum women: a randomized trial," American Journal of Orthopsychiatry, vol. 64, no. 3, pp. 468478, 1994.

[25] W. Barker and R. Anderson, The Child Development Programme, Early Child Development Unit, Bristol, UK, 1984.

[26] Z. Johnson, F. Howell, and B. Molloy, "Community mothers' programme: randomised controlled trial of non-professional intervention in parenting," British Medical Journal, vol. 306, no. 6890, pp. $1449-1452,1993$.

[27] R. M. Bromwich, "The interaction approach to early intervention," Infant Mental Health Journal, vol. 11, no. 1, pp. 66-79, 1990.

[28] M. Lojkasek, N. J. Cohen, and E. Muir, "Where is the infant in infant intervention? A review of the literature on changing troubled mother-infant relationships," Psychotherapy, vol. 31, no. 1, pp. 208-220, 1994.

[29] Home-Start, What We Do, http://www.home-start.org.uk/ about_us/what_we_do/support_services, 2012.

[30] N. Frost, L. Johnson, M. Stein, and L. Wallis, Negotiated Friendship: Home-Start and the Delivery of Family Support, Home-Start UK, Leicester, UK, 1996.

[31] S. Shinman, Family Album: Snapshots of Home-Start in Words and Pictures, Home-Start UK, Leicester, UK, 1994.

[32] W. van der Eyken, Home-Start: A Four-Year Evaluation, HomeStart UK, Leicester, UK, 1982.

[33] C. McAuley, M. Knapp, J. Beecham, N. McCurry, and M. Sleed, Young Families Under Stress. Outcomes and Costs of Home-Start Support, Joseph Rowntree Foundation, York, UK, 2004.

[34] J. Barnes, K. MacPherson, and R. Senior, "The impact on parenting and the home environment of early support to mothers and new babies," Journal of Children'S Services, vol. 1, no. 4, pp. 4-20, 2006.

[35] J. Barnes, R. Senior, and K. MacPherson, "The utility of volunteer home-visiting support to prevent maternal depression in the first year of life," Child, vol. 35, no. 6, pp. 807-816, 2009.

[36] J. Astuto and L. Allen, "Home visitation and young children: an approach worth investing in?" Social Policy Report XXIII (IV), 3-21, 2009.

[37] A. F. Osborn, N. Butler, and A. C. Morris, The Social Life of Britain's 5-year-Olds, Routledge, London, UK, 1984.

[38] B. Jarman, "Underprivileged areas: validation and distribution of scores," British Medical Journal, vol. 289, no. 6458, pp. 15871592, 1984.

[39] J. Barnes, K. MacPherson, and R. Senior, "Factors influencing the acceptance of volunteer home-visiting support offered to families with new babies," Child and Family Social Work, vol. 11, no. 2, pp. 107-117, 2006.

[40] K. MacPherson, J. Barnes, M. Nichols, and S. Dixon, "Volunteer support for mothers with new babies: perceptions of need and support received," Children and Society, vol. 24, no. 3, pp. 175-187, 2010.

[41] S. Shribman and K. Billingham, Health Child Programme: Pregnancy and the First Five Years of Life, Department of Health, London, UK, 2009.

[42] J. L. Cox, J. M. Holden, and R. Sagovsky, "Detection of postnatal depression: development of the 10-item Edinburgh postnatal depression scale," British Journal of Psychiatry, vol. 150, pp. 782-786, 1987.
[43] R. Abidin, Parenting Stress Index (3rd Edition): Professional Manual, Psychological Assessment Resources, Inc, Lutz, Fla, USA, 1995.

[44] B. Caldwell and R. Bradley, Home Observation For Measurement of the Environment: Administration Manual, University of Arkansas, Arkansas, Ark, USA, 3rd edition, 2001.

[45] J. E. Bates, C. A. Freeland, and M. L. Lounsbury, "Measurement of infant difficultness," Child development, vol. 50, no. 3, pp. 794-803, 1979.

[46] N. Bayley, Bayley Scales of Infant Development (2nd Edition): Manual, The Psychological Corporation, Harcourt Brace \& Co, San Antonio, Tex, USA, 1993. 


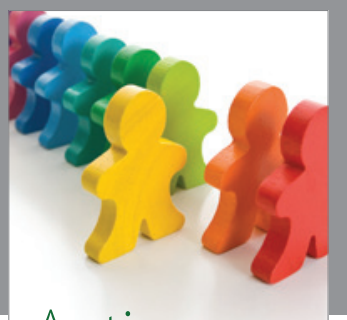

Autism

Research and Treatment
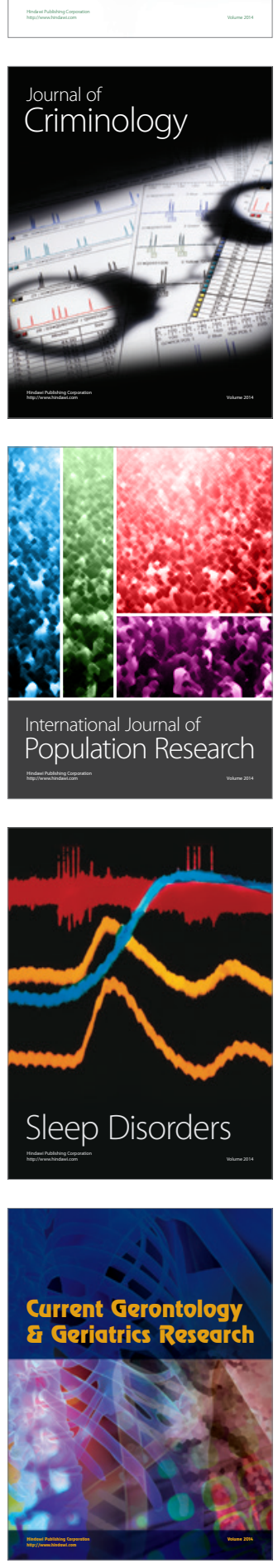
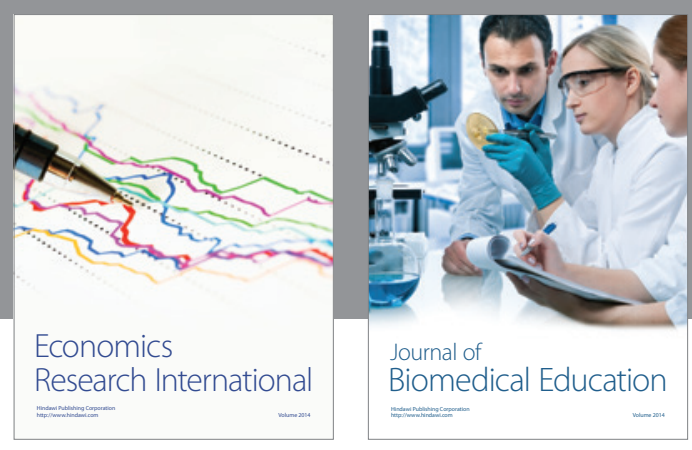

Journal of

Biomedical Education

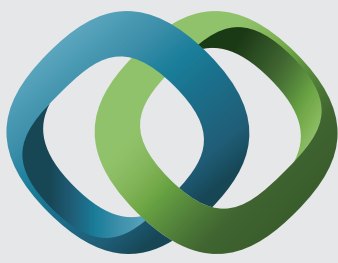

\section{Hindawi}

Submit your manuscripts at

http://www.hindawi.com
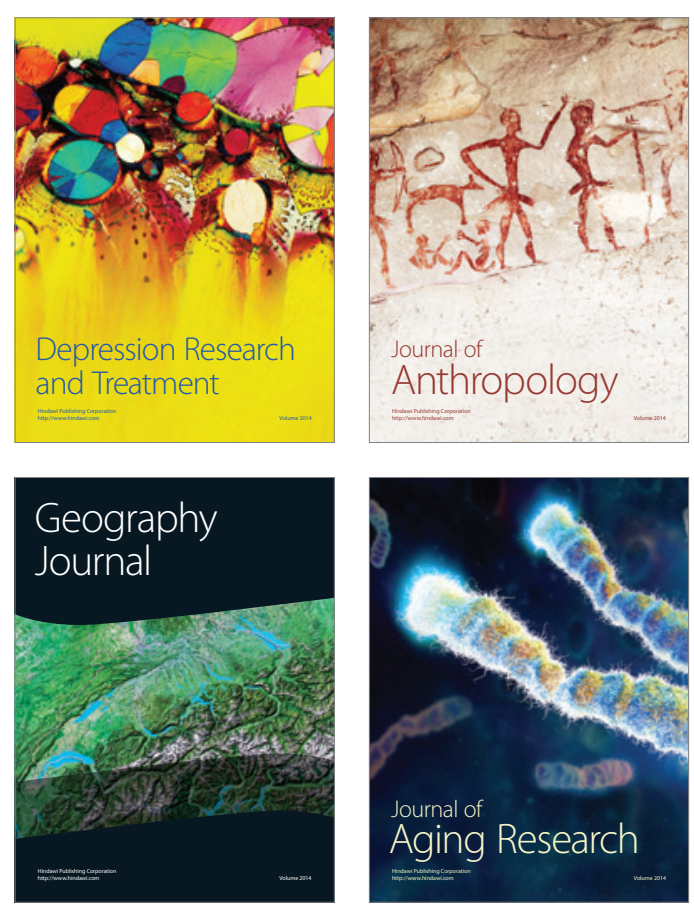

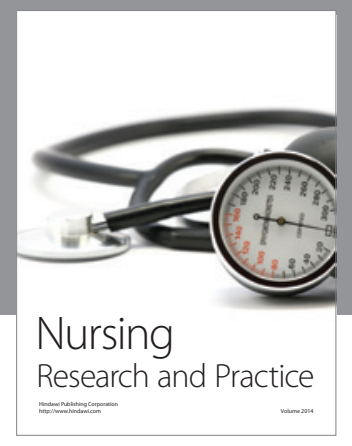

Nursing

Research and Practice

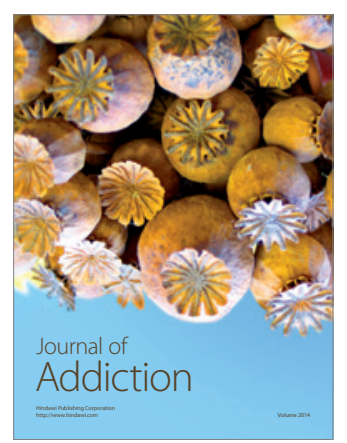

Child Development

Research

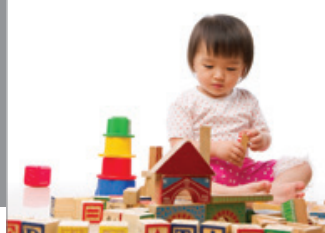

迥
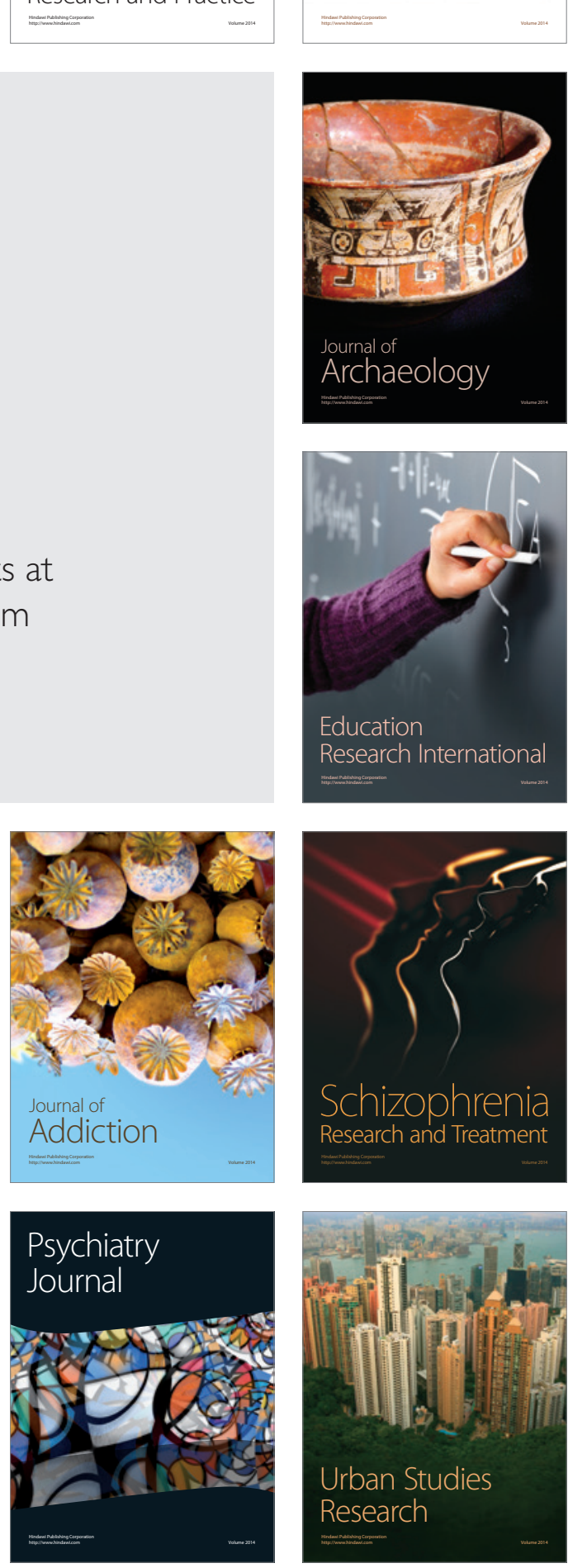